\title{
The utility of point of care serum lactate in predicting serious adverse outcomes among critically ill adult patients at urban emergency departments of tertiary hospitals in Tanzania
}

\author{
Uwezo Edward ${ }^{1}$, Hendry R. Sawe ${ }^{1,2^{*}}$ (D), Juma A. Mfinanga ${ }^{1,2}$, Theresia A. Ottaru ${ }^{3}$, Michael Kiremeji ${ }^{1}$,
}

Deus N. Kitapondya', Dereck A. Kaale ${ }^{1}$, Asha lyullu' ${ }^{1}$, Nicks Bret ${ }^{4}$ and Ellen J. Weber ${ }^{5}$

\begin{abstract}
Background: Elevated serum lactate levels have been shown in numerous studies to be associated with serious adverse events, including mortality. Point of care lactate level is increasingly available in resource-limited emergency department (ED) settings. However, little is known about the predictive ability of for serious adverse events.

Aim of the study: We aimed to describe the utility of serum lactate level as a predictor of 24-h serious adverse events among adult patients presenting at the Emergency Medicine Department (EMD) of Muhimbili National Hospital (MNH) and MUHAS Academic Medical Center (MAMC).

Methods: This was a prospective observational study involving adult patients presenting to the EMD-MNH and MAMC from 1 September 2018 and 31 October 2018. Eligible patients with at least one lactate level test drawn while in the ED were examined in terms of their demographics, relevant clinical characteristics, and any serious adverse event (SAE) within $24 \mathrm{~h}$ of arrival. The sensitivity and specificity of lactate level to predict outcomes of interest were determined using the best cut-off point constructed from AUROC to see how well lactate level could discriminate which patients would have adverse events in the next $24 \mathrm{~h}$. Categorical and continuous variables were compared with the chi-square test and two-sample $t$ test, respectively.

(Continued on next page)
\end{abstract}

\footnotetext{
*Correspondence: hendry_sawe@yahoo.com

'Emergency Medicine Department, Muhimbili University of Health and Allied

Science, P.O. Box 65001, Dar es Salaam, Tanzania

${ }^{2}$ Emergency Medicine Department, Muhimbili National Hospital, Dar es

Salaam, Tanzania

Full list of author information is available at the end of the article
}

(c) The Author(s). 2019 Open Access This article is distributed under the terms of the Creative Commons Attribution 4.0 International License (http://creativecommons.org/licenses/by/4.0/), which permits unrestricted use, distribution, and reproduction in any medium, provided you give appropriate credit to the original author(s) and the source, provide a link to the Creative Commons license, and indicate if changes were made. The Creative Commons Public Domain Dedication waiver (http://creativecommons.org/publicdomain/zero/1.0/) applies to the data made available in this article, unless otherwise stated. 
(Continued from previous page)

Results: We screened 2057 (20.9\%) out of 9828 patients who presented during study period, and enrolled 387 (18.8\%). The overall median age was 54 years (interquartile range 40-68 years) and 206 (53.2\%) were male. Using local triaging system, a total of 322 (83.2\%) was triaged as an emergency category. The mean lactate level was $3.2 \pm 3.6 \mathrm{mmol} / \mathrm{L}, 65$ (16.8\%) patients developed at least one SAE, with 42 (11\%) who required ICU/HDU, 37 (10\%) needed ventilator support, 10 (3\%) required inotropes, and $9(2 \%)$ developed cardiac arrest. The overall 24-h mortality was 28 (7\%). The AUC of serum lactate level for overall $24-\mathrm{h}$ mortality was $0.801(95 \% \mathrm{Cl}, 0.7-0.9, P \leq 0.001)$. At the optimal cutoff value $(3.8 \mathrm{mmol} / \mathrm{L})$, lactate level had a sensitivity and specificity for $24-\mathrm{h}$ mortality of $64 \%$ and $85 \%$, respectively. Mortality of the high-lactate level group $(33.8 \mathrm{mmol} / \mathrm{L})$ was significantly higher than that of the low-lactate level group ( $<3.8 \mathrm{mmol} / \mathrm{L}), 23.8 \% \mathrm{vs}$. $2.9 \%$, respectively $(95 \% \mathrm{Cl} 3.8-17.2, p<0.001)$, with the relative risk of mortality in the high-lactate level group being 8.1 times higher compared to the low-lactate level group.

Conclusion: The utility of lactate level in predicting mortality was similar to that seen in high-resource settings. A serum lactate level of ${ }^{3} 3.8 \mathrm{mmol} / \mathrm{L}$ predicted 24 -h serious adverse events in unselected patients seen in the highacuity area of our ED. Incorporating serum lactate level in ED in lower- and middle-income countries (LMICS) can help identify patients at risk of developing serious adverse events.

Keywords: Lactate level, Serious adverse outcomes, Emergency medicine, Emergency care, Tanzania,

\section{Background}

High-lactate level has been linked to an increased risk of overall mortality in a wide range of populations, including adults and the elderly, regardless of whether they have infections or not $[1,2]$. Elevated lactate level is a marker of poor organ perfusion and has shown to be useful as a marker of poor prognosis in clinically ill patients [3-5]. Most of the literature-based in clinical settings has focused on sepsis and septic shock [6-10]. However, there are many causes of elevated lactate level besides those related to sepsis, which include cardiac arrest, trauma, seizures, ischemia, diabetic ketoacidosis, thiamine deficiency, malignancy, liver dysfunction, genetic disorders, toxins, medications, or any form of shock [11-14]. Recent literature suggests a lactate level less than $2 \mathrm{mmol} / \mathrm{l}$ as normal whilst lactate level above 4 $\mathrm{mmol} / \mathrm{l}$ has an association with increased mortality and longer hospital stay $[2,5,10]$.

The availability and utilization of lactate level testing, especially blood gas point-of-care (POC) testing, has increased worldwide, especially in emergency settings [10]. Despite the wide use of POC lactate level in the developed world and its promise in improving patient care $[10,14-16]$, there is a paucity of African-based studies on the utility of this biomarker, a few of which include (1) serum lactate level as a biomarker for intestinal ischemia done in Uganda [15], (2) point-of-care lactate level testing predicts mortality of severe sepsis in a predominantly HIV type 1 in Uganda [16], and (3) POC lactate level analysis in obstetric sick patients done in 2016 in Malawi [17]. In Tanzania, one study was done at Kilimanjaro Catholic Medical Center (KCMC) which assessed blood lactate level in children presenting to the hospital with febrile illnesses [18]. Most of these studies were done on selected diseases and populations. The "surviving sepsis campaign" integrated lactate level into "early goal-directed therapy" as a marker of adequate resuscitation and monitoring [8]. Some centers have included lactate level as a triaging tool for risk stratification and a predictor of poor outcomes in the ED population [19, 20]. Early illness recognition and early resuscitation with a focus on early lactate level clearance have been shown to improve outcomes in sepsis $[10,19,21]$. Although, it is not known if lactate level is useful in resource-limited settings, where there is a broad, undiagnosed, and untreated disease burden presenting in an undifferentiated manner.

We intended to investigate the utility of POC lactate level and its capacity for predicting serious adverse outcomes in critically ill adult patients presenting to the emergency department and triaged to the resuscitation rooms regardless of the underlying disease conditions.

\section{Methods \\ Study design}

This was a prospective, observational study of a convenience sample of adult ( $>18$ years of age) patients presenting to the Emergency Medicine Department of Muhimbili National Hospital and MUHAS Academy Medical Centers who had at least one POC lactate level result within $1 \mathrm{~h}$ of arrival to the Emergency Medicine Department during the period of study. Ethical approval was obtained from the Institution review board of MUHAS (IRB) and Muhimbili National Hospital (MNH) ethical boards.

\section{Study setting}

This study was conducted in the emergency departments of two hospitals in Dar-es-Salaam, Tanzania: Muhimbili National Hospital (MNH) and MUHAS Academic 
Medical Center (MAMC). MNH is located in the Ilala district, along the United Nations Road in Upanga. It has a bed capacity of 1500 and serves as a referral hospital for the whole of Tanzania. The ED was established in 2010 through a partnership between the Ministry of Health and Social Welfare and the Abbott Fund Tanzania. The ED is the first full capacity public ED in Tanzania and the site for the emergency medicine (EM) residency training program. The department is staffed $24 \mathrm{~h}, 7$ days a week by trained emergency medicine specialists, who oversee the care of patients and supervise interns, registrars, and EM residents. The ED sees an average of 45,000 patients annually with an admission rate of $65 \%$ [22].

MAMC is a recently inaugurated full capacity health facility occupying 3800 acres, located $3 \mathrm{~km}$ off the Dares-Salaam-Morogoro highway, approximately $31.2 \mathrm{~km}$ from $\mathrm{MNH}$. The state-of-the-art emergency medicine department is operating under the direction of an emergency medicine specialist faculty from MUHAS 24-h a day who provides clinical supervision on patients care given by intern doctors, registrars, and emergency medicine residents. Nearly all admissions to these two hospitals come through the emergency medicine departments as the main entry point.

\section{Study protocol}

The study inclusion criteria were adults, aged 18 years or older, who were triaged into resuscitation rooms using the Emergency Severity Index (ESI), with initial serum lactate levels obtained while in the ED, both at MAMC and MUHAS within the first hour of arrival. Written informed consent was provided and signed on approval to all screened patients before enrolment. Venous blood samples were drawn at the discretion of the treating physician as a standardized practice in the ED. At both facilities, lactate level was evaluated using a point of care test (i-STAT ${ }^{\circ} 1$ analyzer MN: 300-G manufactured by Flextronics manufacturing Singapore Pte Ltd., for Abbott Point of Care Inc. USA 2013). This portable clinical analyzer device uses the i-STAT lactate level cartridges and requires approximately $2.5 \mathrm{~mL}$ of blood in a heparinized syringe. The blood was drawn by clinicians in the ED and analyzed by a trained technician: 2 to 3 drops of blood was inserted into the cartridge; then, the cartridge was inserted into the analyzer, and results were available in approximately $2 \mathrm{~min}$. Test results were uploaded manually by nurses or the attending clinician in the WellSoft electronic medical record system used at the emergency medicine departments. Admitted patients were followed up in their respective disposition ward

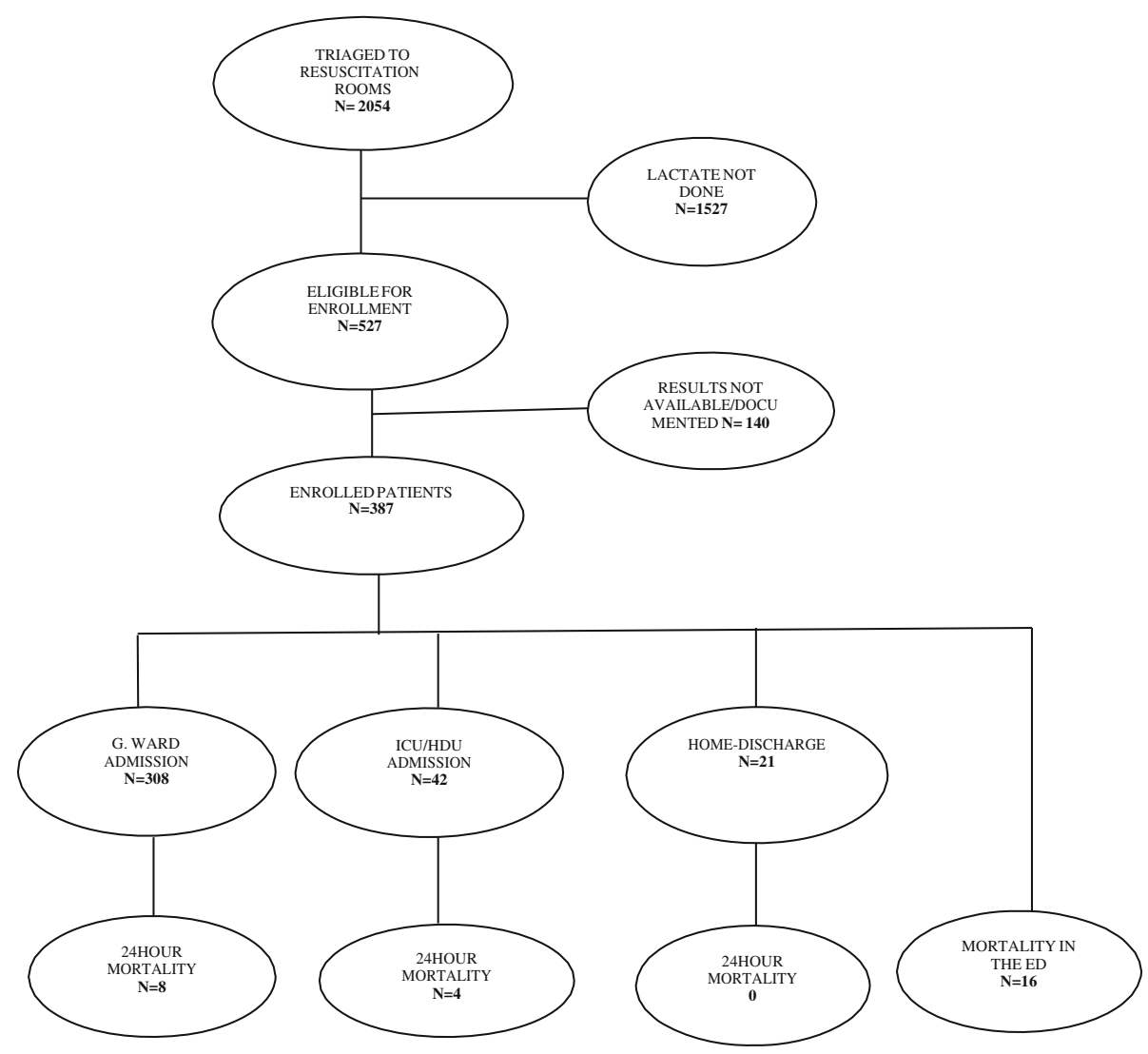

Fig. 1 Study flow diagram 
manually within $24 \mathrm{~h}$ and those who were discharged from the ED received a phone call after $24 \mathrm{~h}$ for outcomes by the research assistants. We defined serious adverse outcomes as the need for ICU/HDU, vasopressor/ inotropes, cardiac arrest, mechanical ventilator support, and overall mortality.

\section{Data analysis}

Data was entered in online data Capture Software (REDCap version 7.2.2, Vanderbilt, Nashville, TN, USA) and the data was exported to Statistical Package for Social Science (SPSS version 23.0, IBM, Ltd., North Carolina, USA) for analysis. Categorical variables were summarized as frequencies and percentages, and continuous variables as means and standard deviations (SD) or medians and interquartile ranges (IQR), depending on data distribution. A receiver operating characteristics curve was constructed for 24-h mortality, and each serious adverse event and the lactate level best cutoff value was chosen as a maximum value on the Youden's index formula [23]. Then, we dichotomized patients into high- and low-lactate level groups respectively based on the optimal cut-off point for 24-h mortality to determine the association between lactate level and clinical presentation, initial laboratory tests, ED management, disposition plan, and serious adverse outcomes. Categorical variables were compared with the chi-square test or Fisher's exact test; two-tailed $p$ values of $<0.05$ were considered statistically significant. All the abnormal vital signs ranges were drawn from a previous study on the association between abnormal vital sign groups and undesirable patient outcomes [24]. Also, the abnormal ranges for blood tests were based on the specifications of our machines (i-STAT ${ }^{\circ} 1$ analyzer MN: 300-G manufactured by Flextronics manufacturing Singapore Pte Ltd., for Abbott Point of Care Inc. USA 2013) and reference ranges were calibrated as per manufacturer instructions. ED admitting diagnosis from patients file were considered for analysis and disease categorization were done based on admitting diagnosis and chief complaints and was only if information's are available at admission.

\section{Results}

We screened 2054 (100\%) patients triaged to resuscitation rooms as level I and II during the study period. Of these, 527 (25.7\%) adult patients had lactate level obtained and they all consented to the study. Of those who consented, $387(73.4 \%)$ had available lactate level results and were included in the final analysis (Fig. 1).

\section{Patient characteristics}

The overall median age was 54 years (interquartile range 40-68 years) and 206 (53.2\%) were male. Three hundred twenty-two (83.2\%) triaged as an emergency category with 195 (50.4\%) being referred from peripheral
Table 1 Patients demographics characteristics

\begin{tabular}{ll}
\hline Variables & $N=387 n(\%)$ \\
\hline Median Age (IQR) & $54(40-68)$ \\
Sex & $206(53.2)$ \\
Male & \\
$<50$ & $165(42.6)$ \\
$>50$ & $222(57.4)$ \\
Referral status & \\
Self-referred & $195(50.4)$ \\
Triage levels & \\
Emergency & $322(83.2)$ \\
Priority & $65(16.8)$ \\
Payment status & \\
Insured & $174(45.0)$ \\
Cash payment & $213(55.0)$ \\
Education profile & \\
Formal education & $340(87.9)$ \\
Informal education & $47(12.1)$ \\
Comorbidities & $14(3.6)$ \\
Diabetes mellitus & $9(2.3)$ \\
HIV & \\
Malignancy & \\
Chronic renal insufficiency & \\
Hypertension & $10.8)$ \\
\hline
\end{tabular}

hospitals and less than half, and 174 (45\%), with insurance coverage. Diabetes mellitus, HIV, and malignancy were the leading comorbidities, 42 (10.8\%), 24 (6.2\%) and $15(3.9 \%)$, respectively (Table 1$)$.

Complaints of general body malaise and abdominal symptoms were the most common chief complaints involving 54 (13.9\% for each), followed by difficulty in breathing and altered mental status. Tachycardia (193, $49.9 \%)$ and tachypnea $(155,40.1 \%)$ were the most frequent abnormal vital signs. Heart failure (46, 11.9\%), malignancies $(43,11.1 \%)$, and cerebrovascular accident (42, 10.8\%) were the leading ED diagnoses. However, infectious $(71,18.3 \%)$ and cardiovascular $(68,17.8 \%)$ represented the main disease categories (Table 2).

\section{EMD laboratory investigations and management plan}

Among the 387 enrolled patients with serum lactate level, the mean lactate level was $3.2 \pm 3.6 \mathrm{mmol} / \mathrm{L}$. Two hundred five $(53 \%)$ had elevated level $\geq 2 \mathrm{mmol} / \mathrm{l}$, with $133(34.4 \%)$ of the total samples having lactate level between 2 to $<4 \mathrm{mmol} / \mathrm{L}$ and $72(18.6 \%)$ of the total having lactate level ${ }^{3} 4 \mathrm{mmol} / \mathrm{L}$. Additional testing was at the discretion of the physician. Of the 380 patients that had sodium tested, 209 (55\%) had hyponatremia, 174 (51.8\%) 
Table 2 Patients baseline variables and clinical characteristics

\begin{tabular}{ll}
\hline Variables & $N=387 n(\%)$ \\
\hline Presenting complaints & \\
General body malaise & $54(13.9)$ \\
Abdominal symptoms & $54(13.9)$ \\
Difficulty in breathing & $30(7.7)$ \\
Altered mental status & $30(7.7)$ \\
Cough & $28(7.2)$ \\
Initial vitals & \\
Tachycardia (HR > 100beat/min) & $193(49.9)$ \\
Tachypnoea (RR > 20breath/min) & $155(40.1)$ \\
Altered mental status (GCS <15) & $91(23.5)$ \\
Hypoxia (SPO2 < 90\%) & $56(14.5)$ \\
Febrile (> 37.9C) & $32(8.3)$ \\
Hypotension (SBP <90 mmHg) & $29(7.5)$ \\
Bradycardia (HR <60beat/min) & $10(2.6)$ \\
ED diagnosis & \\
Heart failure & $46(11.9)$ \\
Malignancies & $43(11.1)$ \\
Cerebrovascular disease & $42(10.8)$ \\
Main disease categories & $46(11.9)$ \\
Infectious & $42(10.9)$ \\
Cardiovascular & \\
Malignancy & \\
\hline & \\
&
\end{tabular}

out of 336 tested had elevated BUN, and creatinine was elevated in $153(47.7 \%)$ out of 321 patients tested. Approximately half of those tested had an abnormal WBC. In the ED, most of the enrolled patients were given intravenous fluids $(328,84.8 \%)$. Although only $18 \%$ of the sample were suspected to have an infectious etiology, $42.9 \%$ received antibiotics. Oxygen therapy was provided to $26.9 \%$ of the patients. Invasive procedures were performed on $22(5.7 \%)$ patients in the ED and $9(2.3 \%)$ underwent cardiopulmonary resuscitation (Table 3 ).

\section{Determining the optimal cut-off value of lactate level to predict adverse events}

A series of receiver operating characteristic curves were plotted to determine the area under the curve (AUROC), and the best cut-off point of lactate level for the following outcomes of interest, for 24-h mortality, need for inotropes/vasopressor, cardiac arrest, need for mechanical ventilator, and overall serious adverse events (SAEs).

\section{Twenty-four-hour mortality}

The lactate level had an AUROC of 0.80 for 24-h mortality (95\% CI, $0.7-0.9, p<0.0001)$. The optimum
Table 3 Patient's EMD laboratory investigations and management plan

\begin{tabular}{|c|c|}
\hline Variables & $n(\%)$ \\
\hline \multicolumn{2}{|l|}{ Laboratory investigations } \\
\hline \multicolumn{2}{|l|}{ Serum lactate mean $3.2 \pm 3.6 \mathrm{mmol} / \mathrm{L}$} \\
\hline \multicolumn{2}{|l|}{ Lactate levels $(\mathrm{mmol} / \mathrm{L}) \mathrm{N}=387$} \\
\hline$<2$ & $182(47.0)$ \\
\hline 2 to $<4$ & $133(34.4)$ \\
\hline$\geq 4$ & $72(18.6)$ \\
\hline Hyponatremia $\left(\mathrm{Na}^{+}<136 \mathrm{mmol} / \mathrm{L}\right), \mathrm{N}=380$ & $209(55)$ \\
\hline High urea (Serum Ur $>6 \mathrm{mmol} / \mathrm{L}$ ), $N=336$ & $174(51.8)$ \\
\hline High creatinine (serum $\mathrm{Cr}>115 \mu \mathrm{mol} / \mathrm{L}$ ), $N=321$ & $153(47.7)$ \\
\hline $\mathrm{WBC}^{\Omega}<4$ or $>11, N=150$ & $71(47.3)$ \\
\hline $\mathrm{PH}$ (acidemia < 7.35), $N=287$ & $100(34.8)$ \\
\hline Hypokalemia $\left(\mathrm{K}^{+}<3.5 \mathrm{mmol} / \mathrm{L}\right), \mathrm{N}=379$ & $112(29.6)$ \\
\hline Hemoglobin $(<7 \mathrm{~g} / \mathrm{dl}), N=266$ & $41(15.4)$ \\
\hline mRDT positive, $N=371$ & $24(13.7)$ \\
\hline Hyperkalemia $\left(\mathrm{K}^{+}>5.5 \mathrm{mmol} / \mathrm{L}\right), N=379$ & $48(12.7)$ \\
\hline Low RBG, N=371 & $19(5.1)$ \\
\hline HIV positive, $N=332$ & $13(3.9)$ \\
\hline \multicolumn{2}{|l|}{ EMD management $(N=387)$} \\
\hline Intravenous fluids & $328(84.8)$ \\
\hline Antibiotics & $166(42.9)$ \\
\hline Oxygen therapy & $104(26.9)$ \\
\hline Intubations & $22(5.7)$ \\
\hline Blood transfusion & $21(5.4)$ \\
\hline Inotropes/vasopressors & $10(2.6)$ \\
\hline Cardiopulmonary resuscitation & $9(2.3)$ \\
\hline
\end{tabular}

${ }^{\Omega}$ Abnormal WBC in cells per cubic millimeter

cut-off value using Youden's Index was $>/=3.8 \mathrm{mmol} / \mathrm{L}$ with sensitivity and specificity of $64 \%$ and $85 \%$, respectively (Fig. 2).

\section{Need for inotrope/vasopressor}

The AUROC for lactate level in predicting the need for inotropes or vasopressors was 0.79 (95\%CI, 0.6-0.9, $p<.002)$. The optimum cut-off value was $3.6 \mathrm{mmol} / \mathrm{L}$ with sensitivity and specificity of $80 \%$ and $80 \%$, respectively (Fig. 3).

\section{Cardiac arrest}

Lactate level predicted cardiac arrest with an AUROC of 0.78 (95\%CI, 0.6-0.9, $p=0.005)$. The optimum cut-off value was $3.5 \mathrm{mmol} / \mathrm{L}$, with sensitivity and specificity of $78 \%$ and $80 \%$, respectively (Fig. 4).

\section{Need for mechanical ventilator support}

The AUROC of lactate level for prediction of mechanical ventilator support was 0.49 (95\%CI, 0.4-0.6, $p=0.790$ ), 


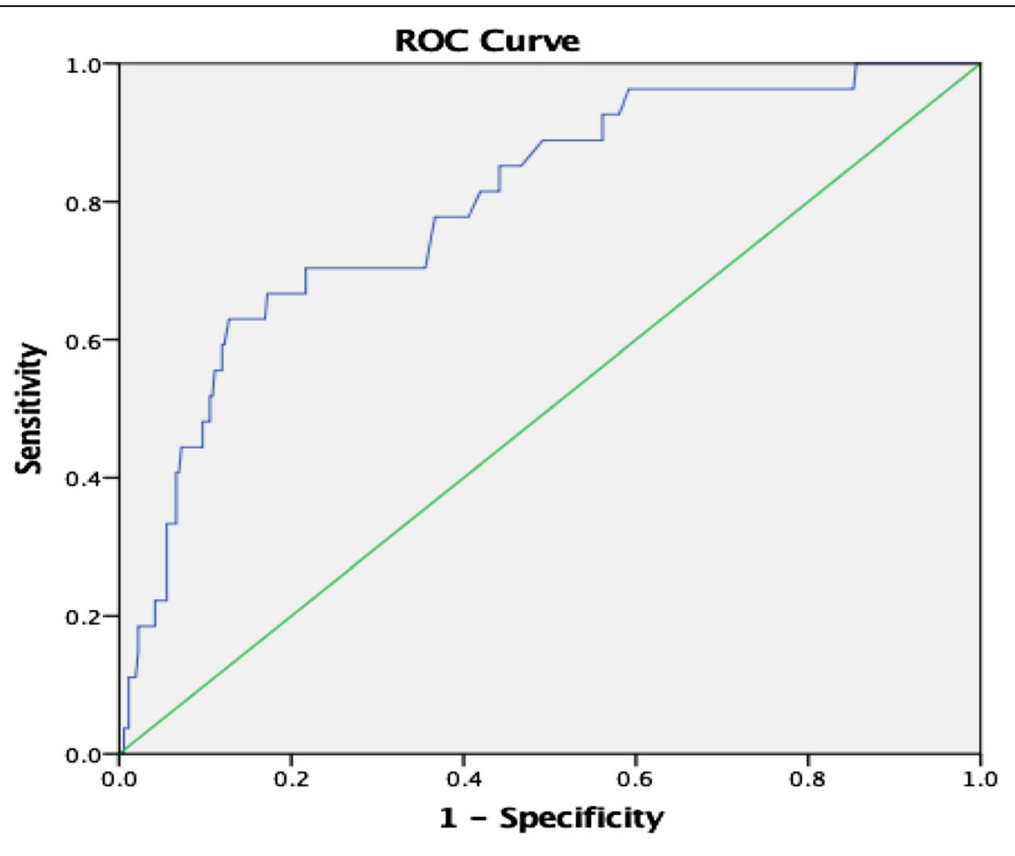

Diagonal segments are produced by ties.

Fig. 2 Graphic representation of ROC curve for 24-h mortality

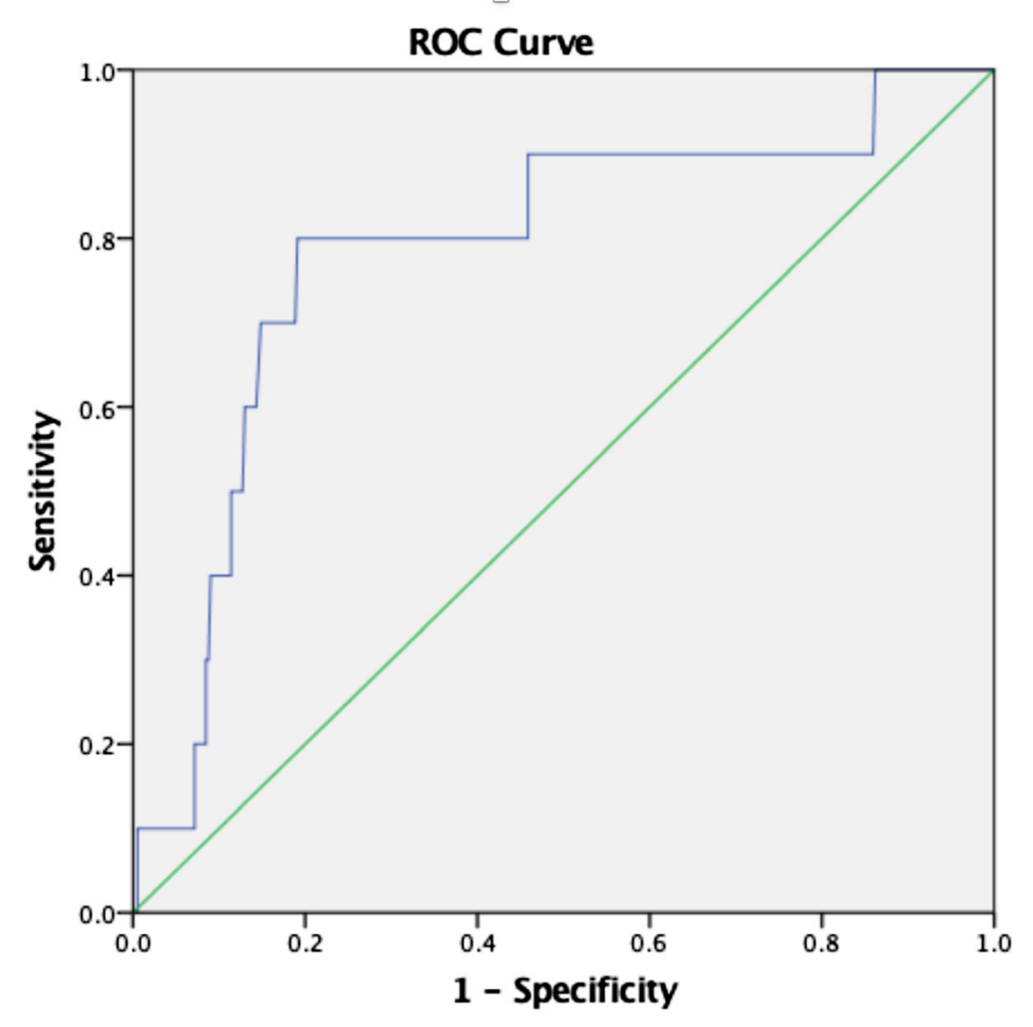

Diagonal segments are produced by ties.

Fig. 3 Graphic representation of ROC curve for need for inotrope/vasopressors 


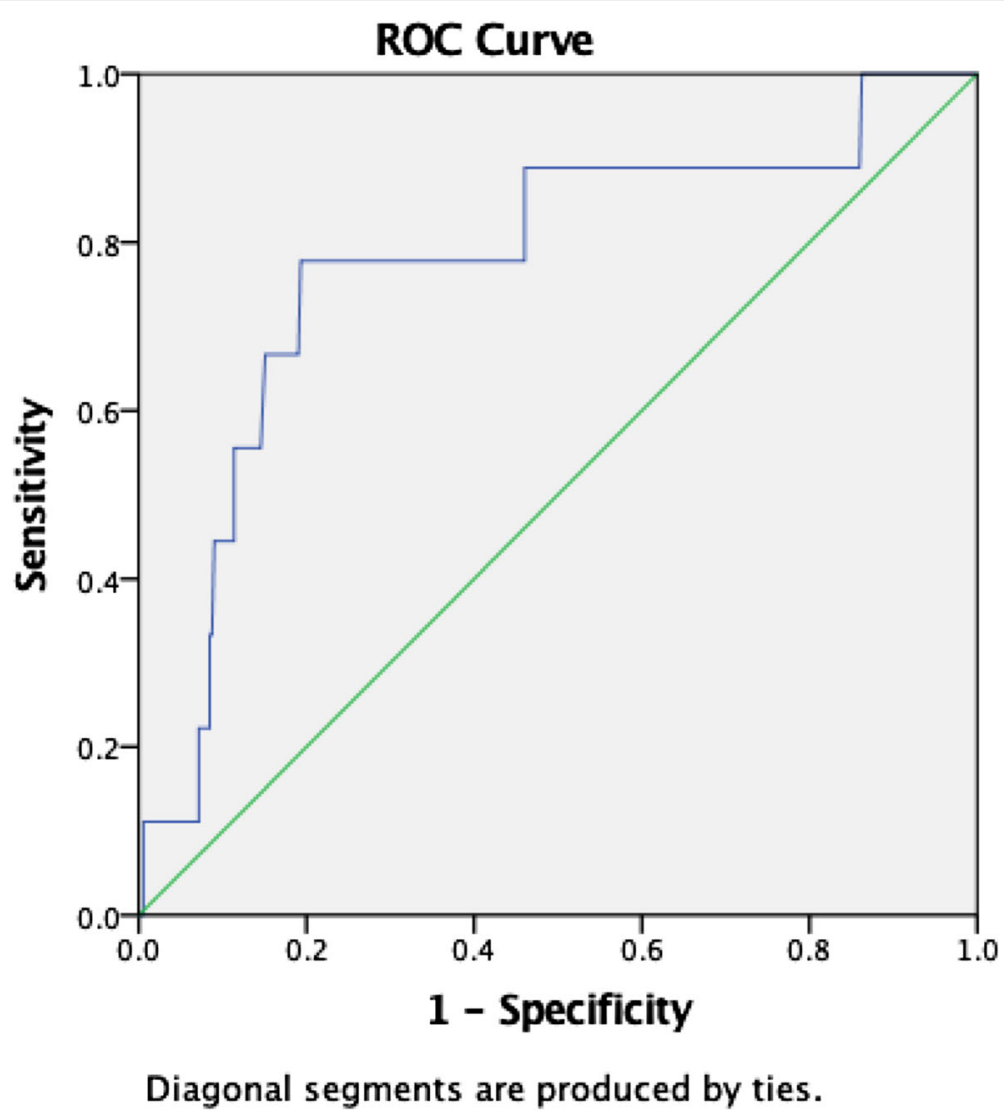

Fig. 4 Graphic representation of ROC curves for cardiac arrest

essentially indicating no discrimination. The optimum cut-off value was $3.4 \mathrm{mmol} / \mathrm{L}$ with sensitivity and specificity of $24 \%$ and $78 \%$, respectively (Fig. 5 ).

\section{Overall serious adverse events (SAEs)}

For any serious adverse event, including mortality, need for vasopressor/inotropes, mechanical ventilation, and cardiac arrest, the AUROC was $0.60(95 \% \mathrm{CI}, 0.5-0.7$, $p=.009)$. The optimum cut-off value was $3.5 \mathrm{mmol} / \mathrm{L}$ with sensitivity and specificity of $40 \%$ and $80 \%$, respectively (Fig. 6).

\section{Baseline variables, laboratory investigation, and management at ED with stratified lactate level}

We used the lactate level associated with 24-h mortality to dichotomize patients into high vs. low lactate level $(\geq$ $3.8 \mathrm{mmol} / \mathrm{L}$ and low $<3.8 \mathrm{mmol} / \mathrm{L}$ ) and determine the association of a high vs. low lactate level with clinical presentation, laboratory investigations performed in the ED, and management at ED. In this study, we found hypotension, tachycardia, tachypnea, and hypoxia all had a significant association with a high lactate level.
Both hyperkalemia and hypokalemia were found to have a statistically significant association with the high lactate level. Lactate level was also significantly associated with low PH level (acidemia), abnormal WBC $(<4$, $>11$ ) and elevated serum urea.

Most of the patients in our study received intravenous fluid $(328,84.8 \%)$, antibiotics $(166,42.9 \%)$ and oxygen therapy $(104,26.9 \%)$ with no statistically significant association to lactate level. However, intubation $(p=0.016)$ and inotropes/vasopressors $(p<0.001)$ were significantly associated with high lactate level (Table 4).

\section{Patient disposition and hospital outcomes}

Those patients in the high-lactate level group were admitted to the general ward $(58,72.5 \%)$, and the ICU (10, $12.5 \%) ; 11$ (13.8\%) died in the ED and one patient (1.3\%) was discharged home. The mortality rate among those with high lactate level admitted to general ward $(4,50 \%)$ was the same as those with low lactate $(50 \%)$ in the lowlactate level group; the mortality was $100 \%$ in ICU for those in the high-lactate level group while there were no deaths in the ICU for patients with lactate level $<3.8$ $\mathrm{mmol} / \mathrm{L}$ with $p=0.002$. The mortality rate in ED among those with a lactate level $\geq 3.8$ was 11 (13.8\%), compared 


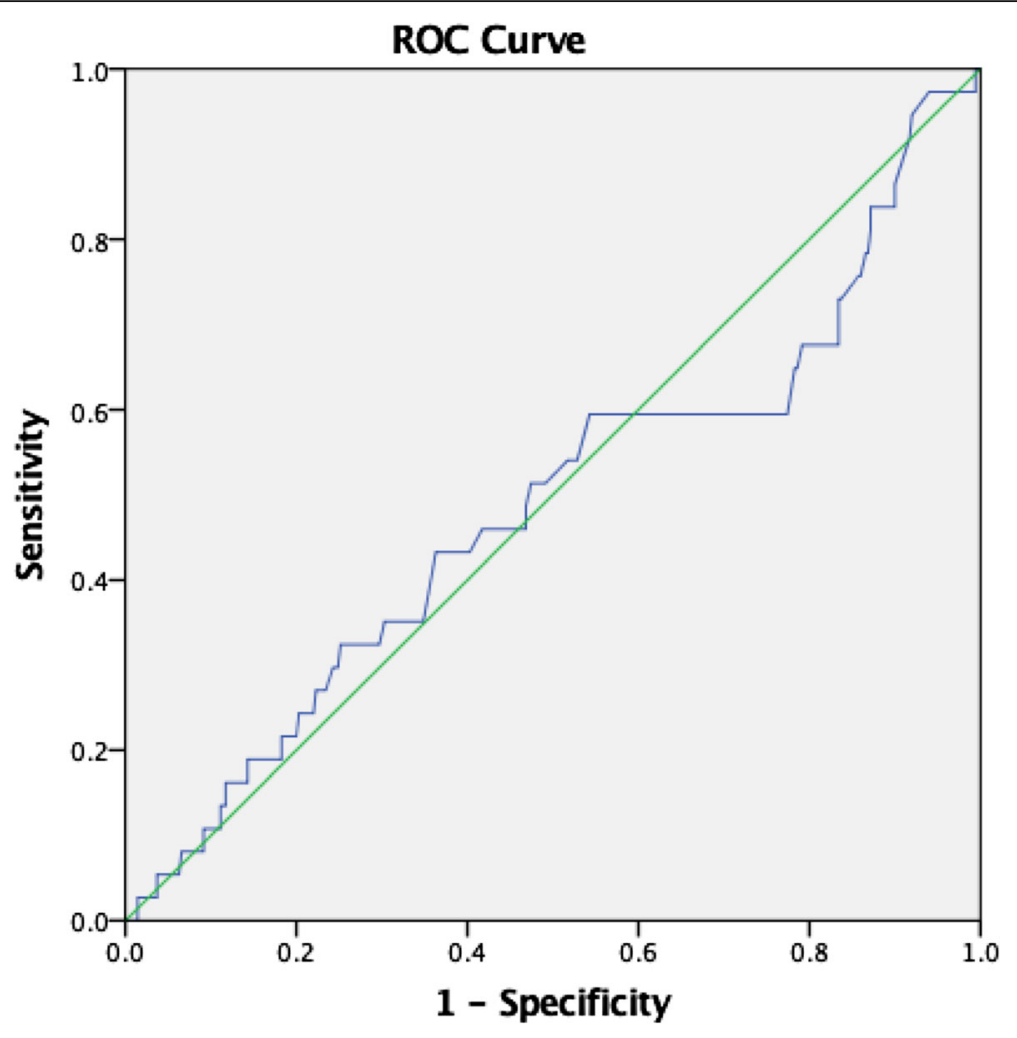

Diagonal segments are produced by ties.

Fig. 5 Graphic representation of ROC curves needs for mechanical ventilator

to $5(1.6 \%)$ for those with lactate level below the cut-off (relative risk 8.4; 95\%CI, 3.0-24, $p=<0.001$ ). The overall mortality at $24 \mathrm{~h}$ was $23.8 \%$ vs. $2.9 \%$ in high- vs. lowlactate level group respectively, with the relative risk of dying within $24 \mathrm{~h}$ being $8.1 \times$ higher in the high-lactate level group compared to those with lactate level $<3.8$ $\mathrm{mmol} / \mathrm{L}$ (Table 5).

Twenty-four-hour serious adverse events with the distribution of high vs. low lactate level (high $<3.8 \mathrm{mmol} /$ $\mathrm{L}$ and low $3.8 \mathrm{mmol} / \mathrm{L}$ )

The relative risk for $24 \mathrm{~h}$ Serious Adverse Events and high vs. low lactate level (high $\geq 3.8 \mathrm{mmol} / \mathrm{L}$ and low $<3.8 \mathrm{mmol} / \mathrm{L}$ ) among our population of the study. The relative risk for requiring a vasopressor was 15.4 (95\%CI, 3.3-70.) and 13.4 (95\%CI, 2.9-63.4) for cardiac arrest among patients with high lactate levelnoting the wide confidence intervals which may reflect the small number of patients for each outcome (Table 5). As predicted from the ROC curve regarding the need for mechanical ventilation and the need for ICU/HDU, there was no association with high lactate level meaning in this study elevated lactate level was not predictive for mechanical ventilation or ICU/ HDU disposition (Table 6).

\section{Discussion}

Emergency medicine is a new specialty in sub-Saharan Africa and having a fully functioning emergency department is an opportunity for quick and timesensitive disease assessment, early resuscitation and stabilization of acutely ill patients with undifferentiated disease conditions. Worldwide, numerous studies have shown an increased level of serum lactate level is associated with amplified risks of developing serious adverse events $[10,25,26]$, but whether that holds in our setting remains unclear. Patients presenting to our ED have a wide variety of diseases, many of which are rare in HIC's, and often present much later in their illness.

In our study looking at serious adverse events for those emergency patients with lactate level obtained during their initial resuscitation, the mean lactate level was $3.2 \pm 3.6 \mathrm{mmol} / \mathrm{L}$. This mean value was low compared to the initial mean lactate level in a study done by Arnold et al. on ED patients with sepsis [27], also low compared to other studies done in similar populations of unselected disease patients in HIC's [2, 28]. The possible reasons could be the diverse study population, inclusion criteria and differing study designs. 


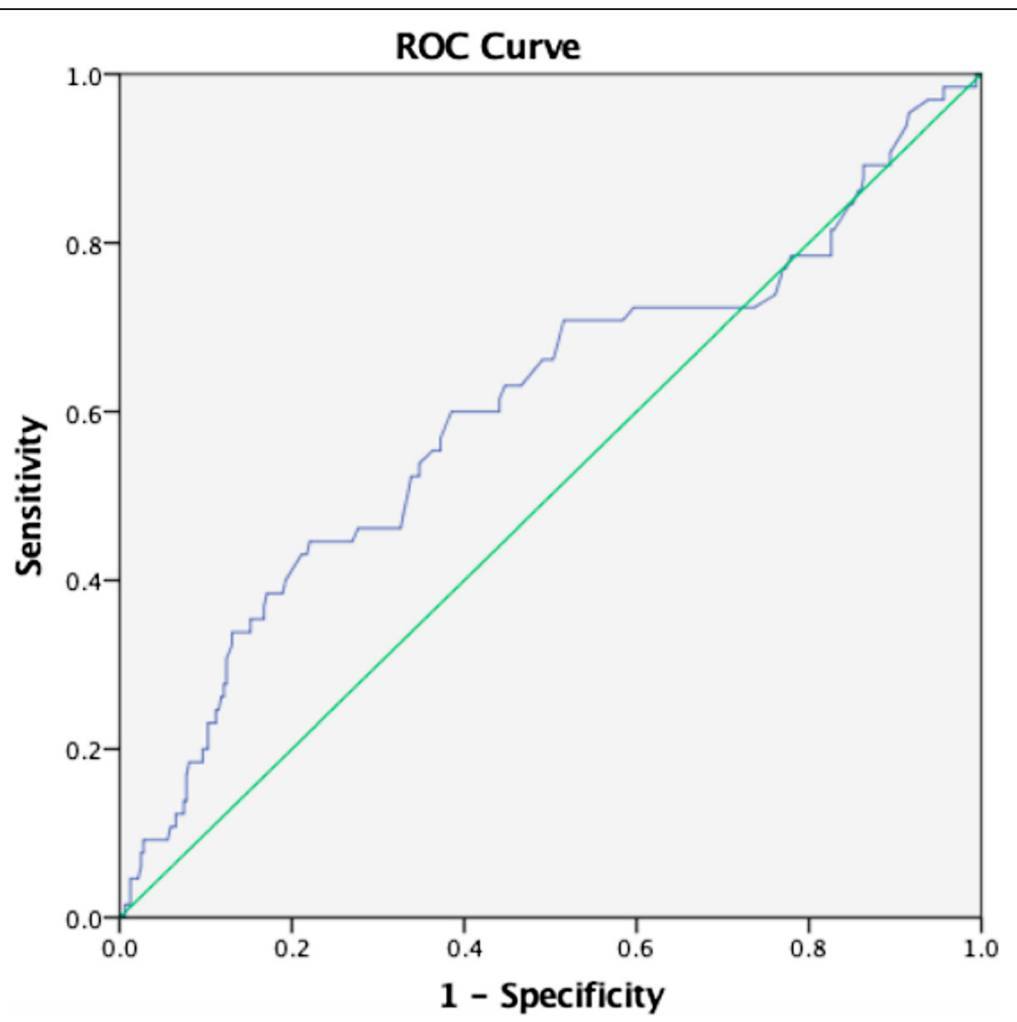

Fig. 6 Graphic representation of ROC curves for overall SAES

In our study, we found clinical characteristics like hypotension, tachycardia, tachypnoea, and hypoxia were statistically related to lactate level, even though some studies have shown lactate level to be higher in hemodynamically stable patients $[13,29]$. Despite clinical characteristics being useful as a marker of patient severity, a study has shown these to have low sensitivity in predicting poor outcomes [27]. We, therefore, recommend the use of lactate level as a marker of poor prognosis in our set up as it is evidenced in our findings that a single lactate level value above $3.8 \mathrm{mmol} / \mathrm{L}$ would predict the critical state of a patient at high risk for mortality.

In this study, we found AUROC for the primary outcome of interest (24-h mortality) was 0.80 , a $p \leq 0.001$ (95\%CI, 0.7-0.9); the best cut-off value for lactate level was $>/=3.8 \mathrm{mmol} / \mathrm{L}$ with sensitivity and specificity of $64 \%$ and $85 \%$, respectively. This is nearly similar to the cut-off of $4 \mathrm{mmol} / \mathrm{L}$ which has been found to have a significant association with SAEs in other settings of HIC's $[4,25,26]$. The discrimination power for mortality was tolerable as per universal standards suggested by Metz CE (0.9-1 excellent, 0.8-0.9 good, 0.7-0.8 fair, 0.6-0.7 poor, 0.5-0.6 fails) [30]. In a systematic review on blood lactate level as a predictor of in-hospital mortality in patients admitted with acutely ill to hospitals lactate level of $(2-4 \mathrm{mmol} / \mathrm{L})$ lactate level had an area under the curve ranging around 0.7 to
0.80. Several studies have shown similar results in specific populations including sepsis, elderly, trauma, and cardiovascular disease $[10,13,25]$.

The overall mortality in $24 \mathrm{~h}$ was 28 (7.3\%), which is low compared to most of the studies done in similar populations in high-income countries. Again, this may be explained by the different settings and study designs noting that many of those studies outcomes were observed for more than $24 \mathrm{~h}$ duration $[2,13,25,28]$.

Based on the AUC for other SAE's, lactate level performed well in predicting cardiac arrest and use of inotropes with a cutoff range of $3.5-3.6 \mathrm{mmol} / \mathrm{L}$, but it did not perform well with the need for mechanical ventilator support or disposition to ICU, although this could be due to the various disease states and variety of patients enrolled, this finding might also be explained by resource constraints in our settings as admission to ICU/ HDU or mechanical ventilation is often based on the ED circumstances and patient prognosis at MNH/MAMC will be factored in to conserve resources.

In this study, patients with abnormal potassium levels, acid-base balance disorders, and abnormal WBC were more likely to be associated with elevated lactate levels, therefore identifying a patient with high lactate levels could help to predict other common underlying abnormalities that could be easily managed in the ED. This can be useful in a resource-limited setting to avoid 
Table 4 Baseline variables, investigations and management by lactate level

\begin{tabular}{|c|c|c|c|c|}
\hline & \multirow{2}{*}{$\begin{array}{l}\text { Overall } \\
N= \\
387 \\
(n)\end{array}$} & \multicolumn{2}{|c|}{ Serum lactate (mmol/L) } & \multirow[t]{2}{*}{$P$ value } \\
\hline & & $\begin{array}{l}<3.8, N=307 \\
n(\%)\end{array}$ & $\begin{array}{l}\geq 3.8, N=80 \\
n(\%)\end{array}$ & \\
\hline \multicolumn{5}{|l|}{ Initial characteristics } \\
\hline Hypotension (SBP < 90 mmHg) & 29 & $13(4.2)$ & $16(20.0)$ & $<0.001$ \\
\hline Tachycardia (HR > 100 beat/min) & 193 & $142(46.3)$ & $51(63.7)$ & 0.005 \\
\hline Bradycardia (HR < 60 beat/min) & 10 & $7(2.3)$ & $3(3.8)$ & 0.438 \\
\hline Tachypnoea (RR > 20 breath/min) & 316 & $242(78.8)$ & $74(92.5)$ & 0.005 \\
\hline Hypoxia ( $\left.{ }^{\Phi} \mathrm{SPO} 2<90 \%\right)$ & 56 & $35(11.4)$ & $21(26.3)$ & 0.001 \\
\hline Febrile $\left({ }^{\oplus} \mathrm{Temp}>37.9^{\circ} \mathrm{C}\right)$ & 32 & $24(7.8)$ & $8(10.0)$ & 0.528 \\
\hline Altered mental status $(\mathrm{GCS}<15)$ & 91 & $69(22.5)$ & $22(27.5)$ & 0.345 \\
\hline \multicolumn{5}{|l|}{ Age (years) } \\
\hline$<50$ & 165 & $120(39.1)$ & $45(56.3)$ & \multirow[t]{2}{*}{0.006} \\
\hline$>50$ & 222 & $187(60.9)$ & $35(43.8)$ & \\
\hline \multicolumn{5}{|l|}{ Laboratory tests } \\
\hline 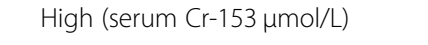 & 153 & $117(38.1)$ & $36(45.0)$ & 0.262 \\
\hline High serum Urea(> $9.7 \mathrm{mmol} / \mathrm{L})$ & 174 & $127(41.4)$ & $47(58.8)$ & 0.005 \\
\hline Hyperkalemia $\left(\mathrm{K}^{+}>5.5 \mathrm{mmol} / \mathrm{L}\right)$ & 338 & $274(89.3)$ & $64(80.0)$ & 0.027 \\
\hline Hypokalemia $\left(\mathrm{K}^{+}<3.5 \mathrm{mmol} / \mathrm{L}\right)$ & 112 & 97 (31.6) & $15(18.8)$ & 0.024 \\
\hline Hyponatremia $\left(\mathrm{Na}^{+}<136 \mathrm{mmol} / \mathrm{L}\right)$ & 209 & $162(52.8)$ & $47(58.8)$ & 0.339 \\
\hline $\mathrm{WBC}^{\mathrm{a}}$ & 77 & $71(23.1)$ & $6(7.5)$ & 0.002 \\
\hline Malaria test positive & 24 & $17(10.1)$ & $7(15.9)$ & 0.290 \\
\hline Hemoglobin $(<7 \mathrm{~g} / \mathrm{dL})$ & 41 & $34(11.1)$ & $7(8.8)$ & 0.547 \\
\hline Low RBG (<3 mmol/L) & 9 & $5(1.6)$ & $4(5.0)$ & 0.092 \\
\hline HIV rapid test positive & 13 & $10(23.6)$ & $3(27.3)$ & 0.709 \\
\hline Acidemia (serum-PH < 7.35) & 100 & $90(29.3)$ & $10(12.5)$ & 0.002 \\
\hline \multicolumn{5}{|l|}{ EMD management } \\
\hline Oxygen therapy & 104 & $87(28.3)$ & $17(21.3)$ & 0.203 \\
\hline Intravenous fluids & 328 & $257(83.7)$ & $71(88.8)$ & 0.264 \\
\hline Blood transfusion & 21 & $15(4.9)$ & $6(7.5)$ & 0.358 \\
\hline Antibiotics & 166 & $130(42.3)$ & $36(45.0)$ & 0.669 \\
\hline Inotropes/vasopressor & 10 & $2(0.7)$ & $8(10.0)$ & $<0.001$ \\
\hline Intubations & 22 & $13(4.2)$ & $9(11.3)$ & 0.016 \\
\hline Cardiopulmonary resuscitation & 9 & $2(0.7)$ & $7(8.8)$ & $<0.001$ \\
\hline
\end{tabular}

${ }^{\Omega}$ Abnormal WBC in cells per cubic millimeter

${ }^{\Phi}$ Saturation of oxygen in peripheral capillary

${ }^{\infty}$ Measurements were all axillary

AMS altered mental status from patients' baseline. Blood transfusion included whole blood and packed RBCS, intravenous fluid-crystalloids

unnecessary testing in patients who are unlikely to have abnormalities.

Generally, our study findings are in keeping with recent literature on the predictive ability of lactate level as a prognostic biomarker of poor outcomes including mortality. Most literature has focused on diseasespecific, e.g., sepsis, trauma $[8,13,25]$ predictions with the risk of poor outcomes being reported to operate in a dose-dependent fashion [4]. In our study, there was a significant difference in SAE's between those with lactate level above ${ }^{3} 3.8 \mathrm{mmol} / \mathrm{L}$ compared to those with a lower level, despite the sensitivity being $64 \%$. Overall, this would result in the exclusion of many patients. If the test was to be designed for screening purposes, especially in the ED, it might be desirable to choose a lower cut-off level with higher sensitivity to maximize capture; however, this may lead to inevitably over triaging, resulting in a greater challenge in terms of costs and sustainability 
Table 5 Patients disposition and hospital outcomes

\begin{tabular}{|c|c|c|c|c|c|}
\hline \multirow[t]{2}{*}{ Variables } & \multirow{2}{*}{$\begin{array}{l}\text { Overall } \\
N= \\
387 \\
n(\%)\end{array}$} & \multicolumn{2}{|c|}{ Serum lactate (mmol/L) } & \multirow{2}{*}{$\begin{array}{l}\text { Relative risk } \\
(95 \% \mathrm{Cl})\end{array}$} & \multirow[t]{2}{*}{$P$ value } \\
\hline & & $\begin{array}{l}<3.8 N=307 \\
n(\%)\end{array}$ & $\begin{array}{l}\geq 3.8 N=80 \\
n(\%)\end{array}$ & & \\
\hline General ward admission & 308 & $250(81.2)$ & $58(72.5)$ & $0.9(0.8-1.0)$ & 0.077 \\
\hline ICU/HDU admission & 42 & $32(10.4)$ & $10(12.5)$ & $1.2(0.6-2.3)$ & 0.595 \\
\hline Discharged home from ED & 21 & $20(6.5)$ & $1(1.3)$ & $0.2(0.0-1.4)$ & 0.092 \\
\hline Death in the ED & 16 & $5(1.6)$ & $11(13.8)$ & $8.4(3.0-24)$ & $<0.001$ \\
\hline Death in ICU/HDU & 4 & $0(0.0)$ & $4(5.0)$ & $5.0(4.1-6.2)$ & 0.002 \\
\hline Death in General ward & 8 & $4(1.3)$ & $4(5.0)$ & $3.8(1.0-15)$ & 0.061 \\
\hline $24 \mathrm{~h}$ mortality & 28 & $9(2.9)$ & $19(23.8)$ & $8.1(3.8-17)$ & $<0.001$ \\
\hline
\end{tabular}

$\mathrm{Cl}$ confidence interval

especially in low-resource countries. In this study, lactate level was obtained using blood gas analyzers which are more expensive compared to a handheld lactate level meter which is less costly [31]. Since it was found that there was a predictive utility of lactate level in our settings, we recommend the procurement of a handheld lactate level meter with lactate level strips to increase the span of coverage and possibly reduce costs.

Several studies have shown the cutoff around 2-4 $\mathrm{mmol} / \mathrm{L}$ and above $4 \mathrm{mmol} / \mathrm{L}$ predicts serious adverse outcomes and our findings are similar $[5,8,25]$. The relationship between illness severity and lactate level is not a new concept but to our knowledge, this was the first study assessing the POC serum lactate level concentration and SAEs in our population. The observed information may be useful for the development of protocolized management to maximize care to the ED population in our settings but also for further studies.

From this study, a cutoff of ${ }^{3} 3.8 \mathrm{mmol} / \mathrm{L}$ and above has shown to have significant association with serious adverse events in our settings, this information may help to guide clinicians in decision-making and prediction of which patient might benefit with aggressive resuscitation, ICU or HDU, admissions and possibly close follow up; however, with development of protocolized management for lactate level clearance in our settings, all these may impact of care of our patient population.

\section{Limitations}

Generalizability of our results may be limited as the study involved two tertiary centers that are $30 \mathrm{~km}$ apart, with the possibility of having similar populations characteristics, this may differ in other settings, particularly in limited-capacity ED found in another place of Tanzania or other LICs. On the other hand, the convenience sampling method was employed and only 387/2054 (18.8\%) of the screened population was enrolled. However, we did not attempt to establish the clinical reasoning behind the decision to order lactate level, and this could be a source of bias as there were possibilities that there was a greater tendency to order lactate level when there was a greater concern of infection or critical illness. If lactate level were ordered routinely, this might result in a large number of false positives hence decreasing the discriminatory power of lactate level.

Some results of lactate level were not recorded in the patient's records despite being ordered and the sample being sent, and the authors did not do follow up on reasons for the missing data hence probably we lost some eligible candidates to this study who may have contributed to the result in terms of deterioration or progress.

\section{Conclusions}

A serum lactate level of $3.8 \mathrm{mmol} / \mathrm{L}$ predicted $24-\mathrm{h}$ serious adverse events in high-acuity patients seen at

Table 6 24-h serious adverse events with distribution of high vs. low lactate level (high $\geq 3.8 \mathrm{mmol} / \mathrm{L}$ and low $<3.8 \mathrm{mmol} / \mathrm{L}$ )

\begin{tabular}{|c|c|c|c|c|c|}
\hline \multirow[t]{2}{*}{ Variables } & \multirow{2}{*}{$\begin{array}{l}\text { Overall } \\
N= \\
387 \\
n(\%)\end{array}$} & \multicolumn{2}{|c|}{ Serum lactate $(\mathrm{mmol} / \mathrm{L})$} & \multirow{2}{*}{$\begin{array}{l}\text { Relative risk } \\
(95 \% \mathrm{Cl})\end{array}$} & \multirow[t]{2}{*}{$P$ value } \\
\hline & & $\begin{array}{l}<3.8 N=307 \\
n(\%)\end{array}$ & $\begin{array}{l}\geq 3.8 N=80 \\
n(\%)\end{array}$ & & \\
\hline Need for inotrope/vasopressor & 10 & $2(0.7)$ & $8(10.0)$ & $15.4(3.3-70.8)$ & $<0.001$ \\
\hline Need for ICU/HDU & 42 & $32(10.4)$ & $10(12.5)$ & $1.2(0.6-2.3)$ & 0.595 \\
\hline Need for ventilator support & 37 & $28(9.1)$ & $9(11.3)$ & $1.2(0.6-2.5)$ & 0.564 \\
\hline Cardiac arrest & 9 & $2(0.7)$ & $7(8.8)$ & $13.4(2.9-63.4)$ & $<0.001$ \\
\hline 24-h mortality & 28 & $9(2.9)$ & $19(23.8)$ & $8.1(3.8-17.2)$ & $<0.001$ \\
\hline
\end{tabular}

Cl confidence interval 
our ED with no regard to any specific illness. Serum lactate level in the ED appears to be useful as a screening tool in a LIMC population to identify patients at risk of SAE; this information can be useful to bedside providers when incorporated into the appropriate clinical scenario and prove useful in clinical research aimed at optimizing and prioritizing care to our population.

\section{Recommendations}

Lactate level appears to be a reasonable test in our settings for alerting providers of critically sick patients at risk of deterioration, but large studies are needed to possibly validate this findings as well as to see if those results are driven by specific diseases.

\section{Abbreviations}

ED: Emergency Department; EMD: Emergency medicine department; ESI: Emergency Severity Index; HDU: High Dependency Unit; HIV: Human Immunodeficiency Virus; ICU: Intensive Care Unit; KCMC: Kilimanjaro Christian Medical Centre; LIC: Low-Income Countries; LMIC: Low- and Middle-Income Countries; MAMC: MUHAS Academic Medical Center; MNH: Muhimbili National Hospital; MUHAS: Muhimbili University of health and allied sciences; SAE: Serious Adverse Events/outcome

\section{Acknowledgements}

The author would like to thank all the study participants, Brit Nicks, Dr. Paulina Nkondora, fellow residents, and research assistants for making this project a success.

\section{Authors' contributions}

UE contributed to the conception and design of the study, acquired, analyzed and interpreted the data, drafted original manuscript, and revised the manuscript. HRS contributed to conception and design of the study, data acquisition, entry, validation, and analysis and also critically revised the manuscript. EJW contributed to conception and design of the study, data validation, review, analysis, and also critically revised the manuscript. NBA contributed to design of the study, review, analysis, and also critically revised the manuscript. All authors read and approved the final manuscript. DNK contributed to the design of the study, and analysis and also revised the manuscript. MK contributed to the conception and design of the study, data cleaning and review, and also revised the manuscript. Al contributed to the conception and design of the study, data cleaning and review, and also revised the manuscript.

\section{Funding}

This was a non-funded project; the principal investigators used their own funds to support the data collection and logistics.

\section{Availability of data and materials}

The dataset supporting the conclusion of this article is available from the authors on request.

\section{Ethics approval and consent to participate}

The study protocol was reviewed and approved by the Institutional Review Board of the Muhimbili University of Health and Allied Sciences' Institutional Review Board (MUHAS-IRB) and permission to collect data was obtained from relevant authorities at MNH. All participants provided a written informed consent prior to participation into the study.

\section{Consent for publication}

Not applicable

\section{Competing interests}

The authors declare that they have no competing interests.

\section{Author details}

${ }^{1}$ Emergency Medicine Department, Muhimbili University of Health and Allied Science, P.O. Box 65001, Dar es Salaam, Tanzania. ${ }^{2}$ Emergency Medicine Department, Muhimbili National Hospital, Dar es Salaam, Tanzania.

${ }^{3}$ Muhimbili University of Health and Allied Science, Dar es Salaam, Tanzania. ${ }^{4}$ Department of Emergency Medicine, Wake Forest School of Medicine, Winston-Salem, NC, USA. ${ }^{5}$ Department of Emergency Medicine, University of California, San Francisco, CA, USA.

Received: 26 July 2019 Accepted: 21 November 2019

Published online: 27 December 2019

\section{References}

1. Oedorf K, Day D, Lior Y, Novack V, Sanchez L, Wolfe R, et al. Serum lactate predicts adverse outcomes in emergency department patients with and without infection. West J Emerg Med. 2017;18(2):258-66.

2. del Portal DA, Shofer F, Mikkelsen ME, Dorsey PJ Jr, Gaieski DF, Goyal M, et al. Emergency department lactate is associated with mortality in older adults admitted with and without infections. Acad Emerg Med. 2010;17(3):260-8.

3. Nichol AD, Egi M, Pettila V, Bellomo R, French C, Hart G, et al. RReesealarchtive hyperlactatemia and hospital mortality in critically ill patients: a retrospective multi-centre study. 2010;9.

4. Shapiro NI, Howell MD, Talmor D, Nathanson LA, Lisbon A, Wolfe RE, et al. Serum lactate as a predictor of mortality in emergency department patients with infection. Ann Emerg Med. 2005;45(5):524-8.

5. Nicks BA, McGinnis HD, Borron SW. Acute lactic acidosis: Overview, Treatment Overview, Pre-hospital Care. 2019. [cited 2019 Dec 5]. Available from: https://emedicine.medscape.com/article/768159-overview

6. Oh DH, Kim MH, Jeong WY, Kim YC, Kim EJ, Song JE, et al. Risk factors for mortality in patients with low lactate level and septic shock. J Microbiol Immunol Infect. 2019;52(3):418-25.

7. Kortz TB, Sawe H, Murray B, Matthay M, Reynolds T. Surviving paediatric sepsis in Tanzania: a prospective cohort study to identify risk factors. Lancet Glob Health. 2017;5:S14.

8. Rhodes A, Evans LE, Alhazzani W, Levy MM, Antonelli M, Ferrer R, et al. Surviving Sepsis Campaign: international guidelines for management of sepsis and septic shock: 2016. Intensive Care Med. 2017;43(3):304-77.

9. Baig MA. Validating a point of care lactate meter in adult patients with sepsis presenting to the emergency department of a tertiary care hospital of a low- to middle-income country. World J Emerg Med. 2017:8(3):184.

10. Tang Y, Choi J, Kim D, Tudtud-Hans L, Li J, Michel A, et al. Clinical predictors of adverse outcome in severe sepsis patients with lactate 2-4 mM admitted to the hospital. QJM. 2015;108(4):279-87.

11. Andersen LW, Mackenhauer J, Roberts JC, Berg KM, Cocchi MN, Donnino MW. Etiology and therapeutic approach to elevated lactate levels. Mayo Clin Proc. 2013;88(10):1127-40.

12. Matsushita K, Williams EK, Mongraw-Chaffin ML, Coresh J, Schmidt MI, Brancati FL, et al. The association of plasma lactate with incident cardiovascular outcomes. Am J Epidemiol. 2013;178(3):401-9.

13. Callaway DW, Shapiro NI, Donnino MW, Baker C, Rosen CL. Serum lactate and base deficit as predictors of mortality in normotensive elderly blunt trauma patients. J Trauma Inj Infect Crit Care. 2009;66(4):1040-4.

14. Cox K, Cocchi MN, Salciccioli JD, Carney E, Howell M, Donnino MW. Prevalence and significance of lactic acidosis in diabetic ketoacidosis. J Crit Care. 2012;27(2):132-7.

15. Kintu-Luwaega R, Galukande M, Owori FN. Serum lactate and phosphate as biomarkers of intestinal ischemia in a Ugandan tertiary hospital: a crosssectional study. Int J Emerg Med. 2013;6(1) Available from: https://intjem. biomedcentral.com/articles/10.1186/1865-1380-6-44. Cited 2019 Jul 8.

16. Moore CC, Jacob ST, Jacob ST, Pinkerton R, Meya DB, Mayanja-Kizza H, et al. Point-of-care lactate testing predicts mortality of severe sepsis in a predominantly HIV type 1-infected patient population in Uganda. Clin Infect Dis. 2008;46(2):215-22.

17. Glasmacher S, Bonongwe P, Stones W. Point-of-care lactate and creatinine analysis for sick obstetric patients at Queen Elizabeth Central Hospital in Blantyre, Malawi: a feasibility study. Malawi Med J. 2016;28(1):15.

18. Mtove G, Nadjm B, Hendriksen ICE, Amos B, Muro F, Todd J, et al. Point-ofcare measurement of blood lactate in children admitted with febrile illness to an African District hospital. Clin Infect Dis. 2011;53(6):548-54.

19. Aramburo A, Todd J, George EC, Kiguli S, Olupot-Olupot P, Opoka RO, et al. Lactate clearance as a prognostic marker of mortality in severely ill febrile 
children in East Africa. BMC Med. 2018;16(1) Available from: https:// bmcmedicine.biomedcentral.com/articles/10.1186/s12916-018-1014-x. Cited 2019 May 31.

20. Bengt Widgren, Ekhardt M. Blood Lactate: A Useful Analysis in Emergency Care, [Internet]. acutecaretesting.org; 2019. [cited 2019 December 5]. Available from: https://acutecaretesting.org/en/articles/blood-lactate-auseful-analysis-in-emergency-care.

21. Dezman ZDW, Comer AC, Smith GS, Narayan M, Scalea TM, Hirshon JM. Failure to clear elevated lactate predicts 24-hour mortality in trauma patients. J Trauma Acute Care Surg. 2015;79(4):580-5.

22. Sawe $H R$, Reynolds $T A$, Mfinanga JA, Runyon MS, Murray BL, Wallis $L A$, et al. The clinical presentation, utilization, and outcome of individuals with sickle cell anaemia presenting to urban emergency department of a tertiary hospital in Tanzania. BMC Hematol. 2018;18(1) Available from: https:// bmchematol.biomedcentral.com/articles/10.1186/s12878-018-0122-3. Cited 2019 Jul 24

23. Youden WJ. Index for rating diagnostic tests. Cancer. 1950;3(1):32-5.

24. Barfod C, Lauritzen M, Danker J, Sölétormos G, Forberg J, Berlac P, et al. Abnormal vital signs are strong predictors for intensive care unit admission and in-hospital mortality in adults triaged in the emergency department - a prospective cohort study. Scand J Trauma Resusc Emerg Med. 2012;20(1):28.

25. Kruse O, Grunnet N, Barfod C. Blood lactate as a predictor for in-hospital mortality in patients admitted acutely to hospital: a systematic review. Scand J Trauma Resusc Emerg Med. 2011;19(1):74.

26. Filho RR, Rocha LL, Corrêa TD, Pessoa CMS, Colombo G, Assuncao MSC. Blood lactate levels cutoff and mortality prediction in sepsis-time for a reappraisal? a retrospective cohort study. Shock. 2016;46(5):480-5.

27. Arnold RC, Shapiro NI, Jones AE, Schorr C, Pope J, Casner E, et al. Multicenter study of early lactate clearance as a determinant of survival in patients with presumed sepsis. Shock. 2009;32(1):35-9.

28. Bou Chebl R, El Khuri C, Shami A, Rajha E, Faris N, Bachir R, et al. Serum lactate is an independent predictor of hospital mortality in critically ill patients in the emergency department: a retrospective study. Scand J Trauma Resusc Emerg Med. 2017;25(1) Available from: http://sjtrem. biomedcentral.com/articles/10.1186/s13049-017-0415-8. Cited 2019 May 31.

29. Puskarich MA, Illich BM, Jones AE. Prognosis of emergency department patients with suspected infection and intermediate lactate levels: a systematic review. J Crit Care. 2014;29(3):334-9.

30. Metz CE. Basic principles of ROC analysis. Semin Nucl Med. 1978;8(4):283-98.

31. Boldt J, Kumle B, Suttner S, Haisch G. This article has been retracted: pointof-care (poc) testing of lactate in the intensive care patient: accuracy, reliability, and costs of different measurement systems. Acta Anaesthesiol Scand. 2001;45(2):194-9.

\section{Publisher's Note}

Springer Nature remains neutral with regard to jurisdictional claims in published maps and institutional affiliations.

Ready to submit your research? Choose BMC and benefit from:

- fast, convenient online submission

- thorough peer review by experienced researchers in your field

- rapid publication on acceptance

- support for research data, including large and complex data types

- gold Open Access which fosters wider collaboration and increased citations

- maximum visibility for your research: over $100 \mathrm{M}$ website views per year

At $\mathrm{BMC}$, research is always in progress.

Learn more biomedcentral.com/submissions 